\section{Original} Article

Access this article online

Website:

www.ajobe.org

DOI:

10.4103/1817-7417.119951

Quick Response Code:

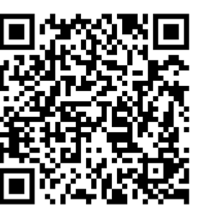

Address for correspondence: Ms. Kemi Ogunyemi,

Lagos Business School, Pan-African University, Km 22, Lekki-Epe Expressway, Ajah-Lagos, Nigeria. E-mail: kogunyemi@lbs.edu.ng

\title{
Ethics education and locus of control: Is Rotter's scale valid for Nigeria?
}

Kemi Ogunyemi

Department of Business Ethics, Lagos Business School, Km 22 Lekki Epe Expressway, Lagos, Nigeria

\section{ABSTRACT}

Managers often face moral decision crossroads that demand self-leadership and require an internal locus of control. This article suggests that the concept of a locus of control should be incorporated into business ethics education in Nigeria, keeping in mind environmental characteristics that inhibit internality, and, based on a qualitative study carried out in Eastern Nigeria, that Rotter's scale be adapted to reduce response bias in this environment. Both incorporation of the concept and adaptation of the scale would be useful in enhancing the ethical reasoning capabilities of future business leaders.

Key words: Business ethics education, emerging economies, locus of control, moral reasoning, Rotter's scale, validation

\section{INTRODUCTION}

Ethical reasoning is the process of arriving at moral judgements. Empirical evidence suggests that the ability to make moral judgements with an intentional orientation is related to an individual's locus of control, and this relationship starts from a very young age (Kenny, Curran, Miller, and Shevlin, 2007; Russell and Phelps, 2009). Locus of control can be external or internal. When it is internal, the person experiences a sense of control over his/her own life; when it is external, the person attributes control over his/her life to external forces, and may tend to adopt a "passive victim lifestyle" (Adams, Kalliny, Santos, and Wang, 2008, p. 110). The effect of an educational intervention or programme that seeks to impart a sense of responsibility in students can be easily undermined by the individual's external locus of control, since locus of control affects ethical decision-making (Forte, 2005; Suryaningrum, Hastuti, and Suhartini, 2013).

In other words, teaching ethical reasoning at tertiary level effectively can be made very difficult by parameters that intensify the students' external locus of control, for example, superstitious beliefs, religiosity and abandonment of traditional wisdom (Connors, 2010; Decker, 2010; Jegede and Okebukola, 1991; Marquette, 2012; Ngwodo, 2005; Ofori-Attah, 2006;
Okafor, 2007; Ukah, 2010). It is, therefore, important for educators at primary, secondary and tertiary levels of education in developing countries, such as Nigeria, to recognise this in their curricula and teaching methods. Otherwise, a prevalent external locus of control will continue to raise already existing levels of unethical behaviour in both the public and private sectors. Until business leaders develop a strong internal locus of control and are able to "self-lead" by freely and responsibly choosing to act ethically, it will be difficult to change the landscape of a business environment that is largely unstructured (Hyatt and Prawitt, 2001) and in which one cannot rely on government and regulatory bodies to ensure fair competition.

One of the mechanisms with which managers tackle complex moral dilemmas has been identified as self-leadership (Van Sandt and Neck, 2003). A self-leader is an individual who is able to reflect on, evaluate and regulate his/ her own actions in order to make appropriate changes for the better (DiLiello and Houghton, 2006; Stewart, Courtright, and Manz, 2011). However, self-leadership is impossible without an internal locus of control (Adams et al., 2008; McDevitt et al., 2007). Business ethics curricula, therefore, not only need to teach students about leadership and self-leadership, but should also be framed in such a way as to foster and encourage the development of an internal locus of control. 
Having an internal locus of control does not in itself guarantee ethical behaviour, but it does make it easier for an individual to "stand against the current" if he/she is desirous of changing things positively. However, no matter how many good desires are generated within business ethics classrooms, individuals with an external locus of control may continue to take their cue from their environment rather than influence it.

Locus of control is developed by personal characteristics, character formation, exposure to societal influences, personal circumstances and life experiences (Dijkstraa, Beersma, and Evers, 2011; Kasilingam and Sudha, 2010; McDevitt et al., 2007). Derived from Carl Jung's work in 1923 , the concept of a locus of control is that individuals are dominated by a tendency to attribute the causes of their actions and life events either to themselves or to external realities (Adams et al., 2008; Forte, 2005; Özen Kutanis, Mesci, and Övdür, 2011). Individuals with an internal locus of control tend to attribute causality to themselves. They are more confident of their ability to influence their environment (Miller, Kets De Vries, and Toulouse, 1982). Individuals with an external locus of control tend to believe that outcomes are determined by outside forces such as luck, fate or powerful others (Hyatt and Prawitt, 2001, p. 266; Rotter, 1975; 1990), and they therefore see little reason to make personal efforts in pursuing such outcomes (Ryan and Francis, 2010), and are unlikely to try to influence those around them (Adams et al., 2008). The concept has been found useful in understanding and guiding human behaviour in its different spheres $(\mathrm{Ng}$, Sorensen, and Eby, 2006), including education and training (Karkoulian and Mahseredjian, 2012; Özen Kutanis, Mesci, and Övdür, 2011).

In light of the above, the objective of this article is to explore the concept of a locus of control and suggest that its measurement scale requires some adaptation in order for it to be useful as a catalyst for achieving greater efficacy in business ethics education in Nigeria. Such adaptation would provide an instrument to detect an external locus of control. It could be a useful tool for more accurately ascertaining the internality or externality of Nigerian managers who easily tend to blame external causes for their behaviour (Ngwodo, 2005; Okafor, 2007; Ugwu, 2011), yet may test internally positive using Rotter's scale.

\section{LITERATURE REVIEW}

Internal locus of control and ethical reasoning

An internal locus of control enables self-leadership, sound moral judgement, and acceptance of responsibility for ethical action (Cherry, 2006; Trevino and Youngblood, 1990), which are indispensable if business ethics educators hope for graduates of business ethics courses to translate ethical principles into ethical action. As explained in the work of Chiu (2003, p. 68) on moderators of whistleblowing intentions, "managers whose locus of control is internal exhibit more consistency between moral judgement and moral action than do managers whose locus of control is external." The idea that ethical action is facilitated by an internal locus of control is also supported by studies on escalating commitment (Street and Street, 2006). Without focussing on ethical action, but rather on decision-making in general, Popoola (2009) explains how self-efficacy (another personality variable that is positively correlated with an internal locus of control) is important for Nigerian managers' decision-making effectiveness ( $\mathrm{Wu}$, Tang, and Kwok, 2004).

\section{Reasons for external locus of control in Nigeria: Environmental factors}

In Nigeria, there are three main forces that drive the external locus of control of many individuals. These are: a high propensity for superstitious beliefs, a level of religiosity as opposed to actual practising of religion, and a tendency to self-doubt that comes from a pervasive practice of despising whatever seems to accentuate a traditional identity, in favour of a westernised version of self (Brownsberger, 1983; Decker, 2010; Jahoda, 1968; Jegede and Okebukola, 1991; Ofori Attah, 2006; Ukah, 2010).

These forces will now be discussed in more detail.

\section{Superstition}

Causality of negative events has often been ascribed to evil forces, especially to witches and wizards, due to the socio-cultural backgrounds of the Nigerian populace (Jegede and Okebukola, 1991). This is still the case now, two decades later, as is evidenced in a recent news article that talks about people who refrain from using safety helmets on motorcycles, in case the previous rider has cast an evil spell on these (Connors, 2010). When a man loses his job or when a graduate does not get a job, the problem is very often ascertained to be a witch or a wizard who is against his progress, and has done something in the spiritual world. Illnesses are often called "spiritual attacks," and the patient may not get the right medical treatment, may delay consulting a doctor, or disbelieve the doctor's diagnosis, since he or she knows the "real" cause of the problem - a wicked mother-in-law, a jealous wife, a temperamental work colleague, wicked spirits from the spirit world (Hardwick, 2002), etc., Thus, locus of control tends to affect health and health practices (Ryan and Francis, 2010). Similarly, failing university entrance exams may not be considered due to a lack of studious preparation, but is ascribed to wicked neighbours and others whom any of the student's family members may have offended in the past.

As far back as 1990, Okebukola and Jegede investigated the effect of superstition on reasoning powers, and showed empirically that students' performance is affected by such 
beliefs. It is interesting that Jahoda (1970) had, much earlier, carried out a study that showed a high level of superstition among Ghanaian students. Such belief in occult powers determining much of what happens to an individual would work to intensify an external locus of control.

\section{Religiosity}

It seems that nine out of every ten Nigerians regard themselves as religious (Ukah, 2010). Indeed, there is a multitude of churches and mosques all over the country, and many of these preach the need to act ethically. Yet, the rate of corruption in the country continues to rise, confirming that the fact that people are religious does not necessarily inform their day-to-day ethical decision-making (Marquette, 2012; Uadiale, Fagbemi, and Ogunleye, 2010). According to Ukah (2010), "religious affectation has been elevated to an art in Nigeria and honed to a fine point." He reports a massacre in Mazah village, Jos, Nigeria, which was followed by an exhortation from the community's leaders to pray for God to avert similar disasters in future, rather than by active efforts to bring the perpetrators to justice or to provide greater security in future.

There is also the trend towards materialism that is promoted by many of the religious leaders, and materialism tends to encourage corruption in a country like Nigeria (Brownsberger, 1983). Many of the religious groups promise wealth and health, and blame demons for the faults of their adherents. Hence, individuals take the cue that they do not need to take a proactive role in developing their character strengths, or take responsibility for their weaknesses and failings. Rather, they move from one congregation to another in futile attempts to cast out the devils that plague them and make them less successful, less rich, less well-behaved, less prestigious, etc., than others. The following excerpt from an article by Ngwodo (2005) on a popular Nigerian news site, www.NigerianVillageSquare. com, aptly describes this phenomenon:

"...latent mass hysteria is what much of the religious establishment has tapped into... In the light of poverty and economic hardship, a gospel of material gain as against spiritual enlightenment is more attractive. Salvation can then only be depicted as a vertical upward movement in terms of social status. It is because religion here is mostly fuelled by survival and self gratification that we find ourselves confronted by the social paradox of high religion and low morality.

This current pop religion serves to anaesthetize the masses with fatalism - a sort of 'blessed assurance' that everything is the way it should be because whatever will be will be - and also by ascribing the individual failures which have generated the massive system failure to the mysterious workings of the divine. The net effect is that the notions of individual responsibility and self examination, which are the cornerstones of spirituality, have been de-emphasized in favour of a god of miracles and other assorted heavenly bonanzas. ... This has greatly diminished the impetus for the sort of mass mobilization and social awareness that is needed to reverse the national slide" (Ngwodo, 2005).

\section{Abandonment of traditional wisdom}

There is now a widespread tendency in Nigerians to embrace everything that comes from outside the country as better than which comes from within, such that whatever is traditional tends to be regarded as outdated and no longer valid in a modern, globalised world (Decker, 2010; Ofori-Attah, 2006; Okafor, 2007; Zaidi, 1979). This wholesale jettisoning of a culture that has many good points in its favour also increases a tendency to look to the external for validation of what one does, rather than relying on internalised values, which would support an internal locus of control.

Many Nigerians now tend to doubt whatever comes from tradition, and this leads to a degree of crisis of identity, where values learnt traditionally, when they were growing up, are now mistrusted, and the individual has not formed replacements for these and, therefore, looks to the external world to instruct him/her on what to do.

This orientation towards what comes from outside Nigeria adds to the prevalence of an external locus of control, and it has practical consequences. For example, it may lead to the reasoning that if one is in a place where there is no litter on the floor, one does not throw litter; but if one is in a place where there is litter on the floor, then it is alright to add to it. If one were to operate in an environment that is free of corruption, one may stop being corrupt; but as long as the people around one continue to be corrupt, then one has no choice but to join them (Marquette, 2012). Behaviour according to internally assimilated principles becomes more and more uncommon. Very often, the excuse for paying a bribe is that it is the way business is done in Nigeria, even when the person has not been asked for a bribe in that specific situation, and personally claims to believe that it is wrong to pay a bribe (Marquette, 2012).

The above discussion provides a background for both understanding why Rotter's scale needs contextual adaptation in Nigeria and advocating that insertions of some internal locus of control principles into business ethics curricula can encourage and contribute to building the capacity to execute the desire to behave ethically.

In the two years preceding the paper, three focus groups were held with first-year MBA students at the Lagos Business School, Pan-African University, Nigeria, and one with tertiary education students attending a Leadership Development Programme in Yaba, Lagos. The purpose was to carry out a preliminary assessment of the internality or 
externality of the locus of control of young Nigerians who aspire to leadership positions in the country. This research, though not used directly in the article, helped to establish the need for more investigation of the applicability of Rotter's scale to test Nigerians' locus of control.

The general response indicated that young Nigerians were hearing of the concept of locus of control for the first time, and they reacted with great interest to the idea that they are in control of their lives and should look inwards as well as outwards when trying to allocate blame for negative events in their lives. A number of them took Rotter's test. The majority expressed that their locus of control was external, yet they had high internality scores on Rotter's scale. The few who were shown to already have some degree of an internal locus of control, based both on their performance in Rotter's test and their own self-assessment, indicated that their appreciation of the concept was reinforced.

Some of the responses from the focus groups, however, showed that distrust of whatever is Nigerian, some religious notions, superstitions and a belief in fate or destiny, is a strong source of an external locus of control. In general, there seemed to be a prevalent tendency to simply blame external circumstances for events. The responses support the idea that Nigerians have either an external or a selective locus of control when it comes to civic responsibility or ethical action.

In one of the focus groups, the Rotter's questionnaire was distributed before the discussion started, and respondents appeared to have a predominantly internal locus of control. However, the ensuing discussion indicated that this was not really the case. This would seem to confirm the observations of Boone (1988) and Spector (1982) that respondents to the pure Rotter's scale test tend to give socially desirable answers and thus skew the results. In the effort to create a context-specific internal-external (I-E) measure, there would be a need to control such social desirability influences (Bernardi, 2006; Tourangeau and Yan, 2007).

\section{ROTTER'S SCALE}

A variety of scales have been used in research on locus of control, but Rotter's remains the predominant one $(\mathrm{Ng}$, Sorensen, and Eby, 2006). Rotter's scale consists of 23 pairs of questions that test the degree of internality or externality of the respondent's locus of control. It has been used in research on coping with stress (Dijkstraa, Beersma, and Evers, 2011; Khan, Saleem, and Shahid, 2012), conflict management and problem-solving approaches (Dijkstraa, Beersma, and Evers, 2011), attitudes to health (Jacobs-Lawson, Waddell, and Webb, 2011; Wu et al., 2004), learning dispositions and performance (Özen Kutanis, Mesci, and Övdür, 2011), knowledge practices (Karkoulian and
Mahseredjian, 2012) and ethical behaviour (Suryaningrum, Hastuti, and Suhartini, 2013). An internal locus of control enhances the ability to take control of one's life and the tendency to succeed in life. It also increases the chances of entrepreneurial and intrapreneurial success (Cetin, 2011; Maciel and Carmago, 2010).

When using the scale for self-assessment, participants select one from each pair of beliefs, depending on their agreement with the statements. Each pair contains one internally oriented statement and one externally oriented statement.

For example,

"Without the right breaks, one cannot be an effective leader."

versus

"Capable people who fail to become leaders have not taken advantage of their opportunities" and

"No matter how hard you try, some people just don't like you."

versus

"People who can't get others to like them just don't understand how to get on with others."

The respondent's overall score can be calculated by allocating nil when the statement selected is internal and one point when the statement is external. The scale is scored by totalling the points scored by the individual; the lower the score, the higher the internality of the locus of control. Total scores would thus range from 1 for a very strong internality to 23 for very strong externality.

The scale has since been adapted for specific domains, for example, health (Hill and Bale, 1980; Jacobs-Lawson, Waddell, and Webb, 2011), traffic (Warner, Özkan, and Lajunen, 2010), consumer behaviour (Mundell, Nicholson, and Christodoulou, 2008); for different fields of research, for example, strategy (Hodgkinson, 1992), entrepreneurship (Schjoedt and Shaver, 2012), occupational stress (Evers, Frese, and Cooper, 2000); and for capturing the construct's multidimensionality through Likert scales (Duffy, Schiflett, and Downey, 1977; Kasilingam and Sudha, 2010; Klockars and Varnum, 1975). Reimanis and Posen (1980) warned about the need to consider cultural differences in the application of the instrument.

\section{BUSINESS ETHICS EDUCATION}

Is it possible to teach ethical behaviour, or to give ethical training? This question is a strongly engaging one for business ethicists, especially for those in the field of 
ethics education. The challenge is that the decision to act ethically (or not) in differing circumstances belongs to the individual agent, and those decisions are shaped by many parameters that may not be determined by whether or not that person has received ethics training. It is on record that many people go through courses in business ethics and grow to become business leaders and managers, but are still unable or unwilling to apply the principles to the situations in which they later find themselves (Aliyu, 2010; Dean, Beggs, and Keane, 2010; Ugwr, 2011). This means that there is still something lacking in their ethical training.

Ethical behaviour is influenced by the values individuals hold, and values are not necessarily derived from classroom sessions. Rather, they are derived from repeated choices made by persons who intelligently choose what to do in different situations and, in so doing, create certain habitual ways of thinking, ways of "proacting" and ways of reacting. Thus, it would be very useful if ethics education could target the education of the intelligence. This would be particularly useful if it addressed the ways in which "the will" can be strengthened to make the right choices in different situations. Such educational interventions would help to combat some of the common influences that lead to poor ethical reasoning or the inability to take ethical action.

The forces that foster an inclination to an external locus of control may differ from culture to culture (Reimanis, 1977; Spector, Sanchez, Siu, Salgado, and Ma, 2004). Hence, it would be of interest to study, within each environment, which variables pose difficulties to sound ethical reasoning and to provide an inoculation against this within business education curricula in order to assure soundness or health of the intellectual perception of what is right and wrong and facilitate the choice of the ethical option. Nigeria is deemed an unstructured environment, since the economic and social policies are complex and highly unpredictable, which, therefore, requires actors with high levels of internal locus of control to make a difference (Hyatt and Prawitt, 2001).

Nigeria's typical inhibitors include superstition, religiosity and the jettisoning of traditional and practical wisdom in the search for identification with everything foreign in a globalised world (Connors, 2010; Decker, 2010; Jegede and Okebukola, 1991; Marquette, 2012; Ngwodo, 2005; Ofori-Attah, 2006; Okafor, 2007; Ukah, 2010). These inhibitors have accelerated the spread of corruption and other unethical practices in Nigeria because they promote an external locus of control and, therefore, undermine self-leadership, self-regulation and responsibility (Ngwodo, 2005; Ugwu, 2011). There is, therefore, a need to "teach" an internal locus of control when imparting business ethics education in this and similar environments. This would help to stem the wave of unethical behaviour, especially corruption, which has become almost endemic (Pratt, Ademosu, Adamolekun, Alabi, and Carr, 2011).
Given that the popular Rotter I-E scale of 1966 lacks context specificity (Hodgkinson, 1992; Reimanis, 1977; Reimanis and Posen, 1980; Spector et al., 2002), one could consider adapting the standard locus of control tests to a Nigerian audience. This would allow the researcher to get a more realistic sense of the extent to which Nigerians have an internal locus of control, and to sensitise them to this concept.

Spheres of human endeavour in which Rotter's initial scale has been made context-specific include politics (Davis, 1983), economics (Furnham, 1986), strategic management (Hodgkinson, 1992), work (Hattrup, O' Connell, and Labrador, 2005; Spector et al., 2002; Wang, Bowling, and Eschleman, 2010), teaching and learning (Grimes, Millea, and Woodruff, 2004; Russell and Phelps, 2009) and health (Kongand Shen, 2011; Ryan and Francis, 2010). This article investigates the need for adaptation of Rotter's scale to the Nigerian context.

\section{METHODOLOGY}

A group of 18 young Nigerians responded to Rotter's original questionnaire. The group was made up of people living and studying and/or working in the eastern part of Nigeria, who had shown an interest in doing an MBA at the Lagos Business School, Pan-African University, Nigeria. Thus, they were a convenience sample; a group of individuals aspiring to leadership in Nigerian organisations. They had not had exposure to formal ethics education, but were aware that they would have this exposure if they were admitted to this university. Their ages ranged from 17 to 39 years, and the average age was 26.8 years. There were 7 female and 11 male respondents. The sample is potentially generalisable to the rest of the country, since Maqsud and Muhammad (1981) had found that ethnic differences do not affect locus of control across the country.

Rotter's instrument was administered to the respondents in Enugu State, Nigeria, in March 2012. At the same time, their locus of control was also tested with another instrument (henceforth referred to as the second instrument), designed to elicit qualitative data. The same respondents were asked more general and open questions (provided further below) in order to elicit from them responses that were not biased by social desirability. The responses were expected to be an indication of individuals' general tendencies of cause attribution, and interpretation of their responses was based on what the literature says about the direction of attribution for an internal and external locus of control.

For example, challenges were identified by each individual in response to three open-ended questions - two concerning individual good (living a happy and healthy life) and one concerning common good (governance). They bear some 
comparison to points 12, 28, and 29 on Rotter's scale. The expectation was that, in responding to these simple questions, depending on the individuals' direction of locus of control, they would tend to identify causes as beyond or within their control. The questions were:

- Please mention the five most critical challenges to good governance in Nigeria

- Please mention the five most critical challenges to living a happy life in Nigeria

- Please mention the five most critical challenges to living a healthy life in Nigeria.

In addition to these three questions, the questionnaires recorded demographic information, a self-description of the respondent, and contained questions to ascertain whether or not the terminology used in the second instrument and in Rotter's scale was clear.

The answers to the second instrument were categorised, as shown in the appendix, according to the direction of attribution of causes - whether this was internal or external - thus paralleling the rationale behind Rotter's scale of locus of control, which is also based on an individual's attribution of cause propensity (Adams et al., 2008). The determination of this classification was based on examples in literature of internal or external cause attribution.

\section{RESULTS}

The responses to Rotter's scale showed that every respondent in the sample had a high or moderate internal locus of control. Some of the scores on internality were as high as three points. According to the results, not a single person had an external locus of control. However, the responses to the second instrument did not show the same trend. On the contrary, the respondents showed an overwhelmingly external locus of control. For example, to the question about causes of bad governance in Nigeria, responses included the prevalence of corruption and poor or unethical leadership. When ranking the causes of living an unhappy or unhealthy life, the frequency of attribution to external causes such as poor infrastructure, a weak public health system, insecurity in the country, a weak legal system, and poverty far outnumbered that of internal causes such as poor nutritional habits or unhygienic practices. While these are indeed realities that contribute to an unhealthy and unhappy life, it is interesting that there were few instances of attribution to causes within the control of individuals.

In accordance with the interpretation whereby a score of 1-4 indicates a strong internal locus of control, 5-12 indicates a moderate internal locus of control and 13-23 indicates an external locus of control, the results showed that none of the 18 respondents had an external locus of control, 7 had a strong internal locus of control, while 11 had a moderate internal locus of control.

In the discussion that followed the administration of the two instruments, the respondents were surprised to learn about the concept of a locus of control, and they agreed that Rotter's scale was probably not a comprehensive determinant of their locus of control.

\section{DISCUSSION}

This validation exercise showed that while the respondents had no problem understanding the meaning of the words used in Rotter's instrument, they were swayed by response bias and social desirability bias in answering the questions. Therefore, Rotter's scale may need some degree of adaptation if it is to be used to measure locus of control for Nigerians living in the eastern part of the country. While conceding that perhaps social desirability bias cannot be totally eliminated, the questions would need to be restated in such a way that the answers elicited would be more sincere than rote.

The second instrument gave some idea of the themes on which it is possible to expect answers that are less affected by social desirability bias, more so when the same respondents answered them with seemingly more honesty at the same time as completing the Rotter's scale questionnaire.

Responses to the second instrument showed that bad governance was mostly externally attributed. The responses included widespread corruption, bad or unethical leadership, a weak legal system, a weak electoral process, poor access to information, etc.

There are a number of implications for being able to measure locus of control validly in the Nigerian context. Firstly, there are advantages to having an internal locus of control in an environment where initiative and ethical actions are required for sustainable development and secondly, there are existing inhibitors of internal locus of control that are important to identify and moderate in the effort to achieve ethics education.

\section{LIMITATIONS OF THE STUDY}

This was an exploratory study showing that Rotter's scale may not accurately measure locus of control in the Nigerian context, and perhaps also in the broader African context. This is because cultural factors may affect interpretation of items and create differential response bias. This, together with social desirability bias, may affect the transportability of the measurement (Reimanis, 1977). However, further research is needed in order to establish and test a version 
of the scale that would more accurately measure locus of control in these settings.

The data for the study were collected from only one part of the country. However, the results provide a fundamental indication that Rotter's scale may not accurately measure locus of control for those respondents and, therefore, for the rest of the population.

Also, it is important to note that whatever a person's measure on the continuum of locus of control, that person still retains his or her freedom to act ethically or not. Hence, having an internal locus of control does not mean that the subject will take ethical decisions; it only means that the subject would be more inclined to act at all, and therefore, where there are opportunities to act ethically, it would be easier for a person with an internal locus of control to so act than for a person paralysed by external considerations. This is because a person with an internal locus of control is more aware of personal responsibility to act.

\section{CONCLUSION AND RECCOMMENDATIONS}

Extant research had established that fostering or enhancing an internal locus of control is invaluable for people who are being prepared to be business leaders and hold managerial positions. With this in mind, the researcher looked into existing literature, especially in the fields of psychology and organisational behaviour, to explore the effects of locus of control on moral judgemental abilities and situate them in the context of mediating variables typical of emerging economies such as Nigeria. In addition, the researcher suggests that the importance of developing an internal locus of control needs to be incorporated into business ethics education. This is particularly needed in cultural environments that once were heavily characterised by strong traditional values (Jones, 2005), but have lost this regulatory environment in the frenzy to become "modern" and which experience intense religiosity and endemic corruption (Kukah, 2010, in a presentation on TEDxEuston).

The researcher, therefore, recommends that a business ethics educational curriculum that incorporates a perspective on locus of control can make a difference to the ethical calibration of Nigerian managers. This suggestion is in line with the recommendations of Trevino and Youngblood (1990) and Forte (2005). However, an instrument adapted to context and environment needs to be developed for Nigeria, and perhaps for each different cultural context, in order to get valid results from an attempt to determine people's locus of control. The present qualitative study clearly established this need.

If business students and future business leaders in Nigeria and in other countries facing similar challenges are able to develop or enhance the requisite internal locus of control that will enable them to grow in self-leadership, they will be better able to engage in ethical reasoning when analysing the situations in which they may find themselves. They will be able to visualise and consider ethical dimensions in decision-making, and ultimately lead their businesses in a responsible and sustainable way that is respectful of all stakeholders.

\section{ACKNOWLEDGEMENT}

The author would like to express sincere appreciation to Suzette Viviers and Chris Van Tonder, without whose encouragement this article might not have been published.

\section{REFERENCES}

Adams, R., Kalliny, M., de los Santos, G., and Wang, Y. (2008). Marketing implications of locus of control orientation among college students: Comparisons of Hispanic and Anglo students in the United States. The Marketing Management Journal, 18, 109-20.

Aliyu, A. (2010). Contextual analysis of business ethics practice by multinational companies in Nigeria. In Proceedings of the $2^{\text {nd }}$ Annual International Conference on Business and Public Policy, March 9 - 11, 2010, Available from: http://www.intledgroup.com/UyoUni_2010_ Proceedings.pdf\#page $=1$ [Last accessed on 14 April 2013].

Bernardi, R. A. (2006). Associations between Hofstede's cultural constructs and social desirability response bias. Journal of Business Ethics, 65, 43-53.

Boone, C. (1988). The influence of the locus of control of top managers on company strategy, structure and performance. In Abeele, P.V. (Ed.), Psychology in Micro and Macro Economics: Proceedings of the $13^{\text {th }}$ Annual Colloquium of the International Association for Research in Economic Psychology 1.

Brownsberger, W. N. (1983). Development and governmental corruption Materialism and political fragmentation in Nigeria. The Journal of Modern African Studies, 21, 215-233.

Caliendo, M., Cobb-Clark, D., and Uhlendorff, A. (2010). Locus of control and job search strategies. Discussion Paper 979, German Institute for Economic Research, DIW Berlin, available at http://www.econstor.eu/ dspace/bitstream/10419/36710/1/619519924.pdf [Last accessed on 14 April 2013].

Cetin, F. (2011). The roles of self-efficacy and locus of control in the intrapreneurship. Business and Economics Research Journal, 2, 69-85.

Cherry, J. (2006). The impact of normative influence and locus of control on ethical judgments and intentions: A cross-cultural comparison. Journal of Business Ethics, 68, 113-32.

Chiu, R. K. (2003). Ethical judgment and whistleblowing intention: Examining the moderating role of locus of control. Journal of Business Ethics, 43 (1/2), Business Ethics in the Global Knowledge Economy 65-74.

Connors, W. (2010). Putting a cap on bad juju conjures up a good business. Wall Street Journal - Eastern Edition, 256, (120), A1-A16.

Davis, J. (1983). Does authority generalize? Locus of control perceptions in Anglo-American and Mexican-American adolescents. Political Psychology, 4, 101-20.

Dean, K. L., Beggs, J. M., and Keane, T. P. (2010). Mid-level managers, organizational context, and (un) ethical encounters. Journal of Business Ethics, 97, 51-69.

Decker, S. (2010). Postcolonial transitions in Africa: Decolonization in West Africa and present day South Africa. Journal of Management Studies, 47, 791-813.

DiLiello, T. C. and Houghton, J. D. (2006). Maximizing organizational leadership capacity for the future: Toward a model of self-leadership, innovation and creativity. Journal of Managerial Psychology, 21, 319-33.

Dijkstraa M. T. M., Beersma, B., and Evers, A. (2011). Reducing conflict-related employee strain: The benefits of an internal locus of 
control and a problem-solving conflict management strategy. Work and Stress, 25, 167-84.

Duffy, P. J., Schiflett, S., and Downey, R. G. (1977). Locus of control: Dimensionality and predictability using Likert scales. Journal of Applied Psychology, 62, 214-9.

Evers, A., Frese, M., and Cooper, C. L. (2000). Revisions and further developments of the occupational stress indicator: LISREL results from four Dutch studies. Journal of Occupational and Organizational Psychology, 73, 221-40.

Forte, A. (2005). Locus of control and the moral reasoning of managers. Journal of Business Ethics, 58, 65-77.

Furnham, A. (1986). Economic locus of control, Human Relations 39, $29-43$. Grimes, P. W., Millea, M. J., and Woodruff, T. W. (2004). Grades - Who's to blame? Student evaluation of teaching and locus of control. Journal of Economic Education, 35, 129-47.

Hardwick, R. (2002). Kill or cure? The Lancet, 359, 366.

Hattrup, K., O' Connell, M., and Labrador, J. (2005). Incremental validity of locus of control after controlling for cognitive ability and consciousness. Journal of Business and Psychology 19, 461-81.

Hill, D. J. and Bale, R. M. (1980). Development of the mental health locus of control and mental health locus of origin scales. Journal of Personality Assessment, 44, 148-56.

Hodgkinson, G. P. (1992). Development and validation of the strategic locus of control scale. Strategic Management Journal, 13, 311-7.

Hyatt, T. A. and Prawitt, D. F. (2001). Does congruence between audit structure and auditors' locus of control affect job performance? The Accounting Review, 76, 263-74.

Jacobs-Lawson, J. M., Waddell E. L., and Webb, A. K. (2011). Predictors of health locus of control in older adults. Current Psychology, 30, 173-83. Jahoda, G. (1968). Some research problems in African education. Journal of Social Issues, 24, 161-75.

Jahoda, G. (1970). Supernatural beliefs and changing cognitive structures among Ghanaian university students. Journal of Cross-Cultural Psychology, 1, 115-30.

Jegede, O. J. and Okebukola, P. A. (1991). The effect of instruction on socio-cultural beliefs hindering the learning of science. Journal of Research in Science Teaching, 28, 275-85.

Jones, C. A. (2005). Wisdom paradigms for the enhancement of ethical and profitable business practices. Journal of Business Ethics, 57, 363-75.

Kenny, S., Curran, K., Miller, R., and Shevlin, M. (2007). A voiceXML enabled locus of control scale system designed to engage school pupils lacking commitment in the career development and decision-making process. Georgian Electronic Scientific Journal: Education Science and Psychology, 1, 45-53.

Karkoulian, S. and Mahseredjian, JA. (2012). Prediction of knowledge acquisition, knowledge sharing and knowledge utilization from locus of control: An empirical investigation. Business Studies Journal, 4, 117-30. Kasilingam, R. and Sudha, S. (2010). Influence of locus of control on investment behaviour of individual investor. The Indian Journal of Management, 3, 17-25.

Khan, A. A., Saleem, M., and Shahid, R. (2012). Buffering role of locus of control on stress among the college/university teachers of Bahawalpur. Pakistan Journal of Commerce and Social Sciences, 6, 158-67.

Klockars, A. J. and Varnum, S. W. (1975). A test of the dimensionality assumptions of Rotter's internal-external scale. Journal of Personality Assessment 39, 397-404.

Kong, Y. and Shen, F. (2011). Impact of locus of control on health message effectiveness. Health Marketing Quarterly, 28, 354-71.

Maciel, C. de O. and Carmago, C. (2010). Locus of control, entrepreneurial behavior and performance of small businesses. Revista de Administração Mackenzie, 11, 168-88.

MacLagan, P. (2003). Varieties of moral issue and dilemma: A framework for the analysis of case material in business ethics education. Journal of Business Ethics, 48, 21-32.

Maqsud, M. (1981). Locus of control in Nigerian adolescents and their ethnic membership. The Journal of Social Psychology, 113, 13-9.

Marquette, H. (2012). 'Finding God' or 'moral disengagement' in the fight against corruption in developing countries? Evidence from India and Nigeria. Public Administration and Development, 32, 11-26.

McDevitt, R., Giapponi, C., and Tromley, C. (2007). A model of ethical decision-making: The integration of process and content. Journal of Business Ethics, 73, 219-29.

Miller, D., Kets De Vries, M., and Toulouse, JM. (1982). Top executive locus of control and its relationship to strategy-making, structure, and environment. Academy of Management Journal, 25, 237-53.

Moustakas, C. (1994). Phenomenological research methods. Sage Publications: Thousand Oaks California.

Mundell, M. L., Nicholson, M., and Christodoulou, A. (2008). Locus of control as a person-situation mediator in the consumer behaviour context, Advances in Consumer Research-European Conference Proceedings, 8, 332-33.

Ng, T. W. H., Sorensen, K. L., and Eby, L. T. (2006). Locus of control at work: A meta-analysis. Journal of Organizational Behavior, 27, 1057-87.

Ngwodo, C. (2005). System failure, religion, corruption and violence. Available from: http://www.nigeriavillagesquare.com/articles/ chris-ngwodo/system-failure-religion-corruption-and-violence.html [Last accessed on 14 October 2011].

Ofori-Attah, K. D. (2006). The British and curriculum development in West Africa: A historical discourse. Review of Education, 52, 409-23.

Okafor, E. E. (2007). 'Globalisation, casualisation and capitalist business ethics: A critical overview of the situation in the oil and gas sector in Nigeria. Journal of Social Science, 15, 169-79.

Okebukola, P. A. and Jegede, O. J. (1990). Eco-cultural influences upon students' concept attainment in science. Journal of Research in Science Teaching, 27, 661-9.

Özen Kutanis, R., Mesci, M., and Övdür, Z. (2011). The effects of locus of control on learning performance: A case of an academic organization. Journal of Economic and Social Studies, 1, 113-36.

Popoola, S. O. (2009). Self efficacy, information acquisition and utilization as correlates of effective decision making among managers in insurance companies in Nigeria. Malaysian Journal of Library and Information Science, 14, 1-15.

Pratt, C. B., Ademosu, E. A., Adamolekun, W., Alabi, L., and Carr, R. L. (2011). Managing a crisis of confidence in Nigeria's banking and financial industry. Public Relations Review, 37, 71-3.

Reimanis, G. (1977). Locus of control in American and northeastern Nigerian students, The Journal of Social Psychology, 103, 309-10.

Reimanis, G. and Posen, C. F. (1980). Locus of control and anomie in Western and African cultures. The Journal of Social Psychology, 112, 181-9.

Rotter, J. B. (1966). Generalized expectancies for internal versus external control of reinforcement. Psychological Monographs: General and Applied, 80, 1-28.

Rotter, J. B. (1975). Some problems and misconceptions related to the construct of internal versus external control of reinforcement. Journal of Consulting and Clinical Psychology, 43, 56-7.

Rotter, J. B. (1990). Internal versus external control of reinforcement. American Psychologist, 45, 489-97.

Russell, C. M. and Phelps, C. L. (2009). The effect of mastery-focused goal setting to internalize locus of control and increase academic achievement. In proceedings of the Phi Delta Kappa International Summit on Quality Education Recruitment and Retention, October 15-17, 2009, available at http://www.pdkintl.org/member/docs/R_Russell_Phelps_2009.pdf-[Last accessed on 14 April 2013].

Ryan, M. E. and Francis, A. J. P. (2012). Locus of control beliefs mediate the relationship between religious functioning and psychological health. Journal of Religion and Health, 51, 774-85.

Schjoedt, L. and Shaver, K. (2012). Development and validation of a locus of control scale for the entrepreneurship domain. Small Business Economics, 39, 713-26.

Shapero, A. (1975). The displaced, uncomfortable entrepreneur. Psychology Today, 9, 83-8. Available from: http://ssrn.com/abstract=1506368 [Last accessed on 14 April 2013].

Spector, P. E. (1982). Behaviour in organizations as a function of employees' locus of control. Psychological Bulletin, 91, 482-97.

Spector, P. E. et al. (2002). Locus of control and well-being at work: 
How generalizable are western findings? Academy of Management Journal, 45, 453-66.

Spector, P. E., Sanchez, J. I., Siu, O. L., Salgado, J., and Ma, J. (2004). Eastern versus western control beliefs at work: An investigation of secondary control, socio-instrumental control, and work locus of control in China and the US. Applied Psychology: An International Review, 53, 38-60.

Stewart, G. L., Courtright, S. H., and Manz, C. C. (2011). Self-leadership: A multilevel review. Journal of Management, 37, 185-222.

Street, M. and Street, V. L. (2006). The effects of escalating commitment on ethical decision-making. Journal of Business Ethics, 64, 343-56.

Suryaningrum, D. H., Hastuti, S., and Suhartini, D. (2013). Accounting student and lecturer ethical behavior: Evidence from Indonesia. Business Education and Accreditation, 5, 31-40.

Trevino, L. K. and Youngblood, S. A. (1990). Bad apples in bad barrels: A causal analysis of ethical decision-making behaviour. Journal of Applied Psychology 75, 378-85.

Tourangeau, R. and Yan, T. (2007). Sensitive questions in surveys. Psychological Bulletin, 133, 859-83.

Uadiale, O. M., Fagbemi, T. O., and Ogunleye, J. O. (2010). An empirical study of the relationship between culture and personal income tax evasion in Nigeria. European Journal of Economics, Finance and Administrative Sciences, 20, 116-26.

Ugwu, L. I. (2011). Unethical behaviour in Nigerian organizational settings: Its evolution, dimensions and impact on national development. Asian Social Science, 7, 20-4.
Ukah, J. (2010). Of religion, corruption and happiness. Article in NigeriaPlus, posted on July 27, 2010. Available from: http://www. nigeriaplus.com/of-religion-corruption-and-happiness-by-john-ukah/[Last accessed on 14 October 2011].

VanSandt, C. V. and Neck, C. P. (2003). Bridging ethics and self leadership: Overcoming ethical discrepancies between employee and organizational standards. Journal of Business Ethics, 43, 363-87.

Wang, Q., Bowling, N. A., and Eschleman, K. J. (2010). A meta-analytic examination of work and general locus of control. Journal of Applied Psychology, 95, 761-8.

Warner, H. W., Özkan, T., and Lajunen, T. (2010). Can the traffic locus of control (T-LOC) scale be successfully used to predict Swedish drivers' speeding behaviour? Accident Analysis and Prevention, 42, 1113-7.

Wu, A. M., Tang, C. S., and Kwok, T. C. (2004). Self-efficacy, health locus of control, and psychological distress in elderly Chinese women with chronic illnesses. Aging and Mental Health, 8, 21-8.

Zaidi, S. M. (1979). Values expressed in Nigerian children's drawings. International Journal of Psychology, 14, 163-9.

How to cite this article: Ogunyemi K. Ethics education and locus of control: Is Rotter's scale valid for Nigeria?. Afr J Bus Ethics 2013;7:1-10.

Source of Support: Nil, Conflict of Interest: None declared

\section{AUTHOR}

Kemi Ogunyemi holds a degree in law from the University of Ibadan, an LLM from the University of Strathclyde, and an MBA from the Lagos Business School (LBS), Pan-African University, Nigeria. She teaches business ethics, anthropology and sustainability at the LBS. Her consulting and research interests include personal ethos, life-work ethic, social responsibility, sustainability and governance. She is a member of the EBEN SIG on Teaching Business Ethics and the PRME Anti-corruption Working Group.

\section{APPENDIX}

\begin{tabular}{lcc}
\hline Aggregated responses to the second instrument & & Direction of attribution \\
\hline Hindrances to good governance in Nigeria & Occurrence & External \\
Bureaucracy & 2 & External \\
Cultural differences & 2 & External \\
Godfatherism & 3 & Internal \\
Greed & 2 & External \\
High violent crime rates & 1 & External \\
Illiteracy & 1 & External \\
Inadequacy in policy making and implementation & 2 & Internal \\
Inertia & 1 & Internal \\
Irresponsibility of the Nigerian people & 1 & External \\
Lack of encouragement for innovation & 1 & Internal \\
Lack of patriotism & 1 & Internal \\
Negative mindset & 1 & External \\
Nepotism & 1 & Internal \\
Nonchalance of the electorate & 1 & External \\
Poor access to information & 3 & External \\
Poor and or unethical leadership & 8 & Internal \\
Poor attitude to work & 1 & Internal \\
Poor attitudes & 1 & Contd... \\
\hline
\end{tabular}




\begin{tabular}{|c|c|c|}
\hline \multicolumn{3}{|l|}{ Appendix: Contd... } \\
\hline Poor educational systems & 1 & External \\
\hline Religious differences & 1 & External \\
\hline Religious intolerance & 3 & Internal \\
\hline Self-centredness and disregard for the common good & 3 & Internal \\
\hline Slow economic growth & 1 & External \\
\hline Unemployment & 1 & External \\
\hline Weak electoral institutions & 4 & External \\
\hline Weak legal system & 3 & External \\
\hline Weak security & 2 & External \\
\hline Widespread corruption & 20 & External \\
\hline \multicolumn{3}{|l|}{ Hindrances to living happily and healthily in Nigeria } \\
\hline Access to information & 1 & External \\
\hline Chemicals in modern food & 2 & External \\
\hline Environmental hazards and pollution & 9 & External \\
\hline High inflation & 2 & External \\
\hline High interest rates & 1 & External \\
\hline Ignorance & 4 & Internal \\
\hline Inconsistency in government policy & 1 & External \\
\hline Level of illiteracy & 2 & External \\
\hline Low local food production & 1 & Internal \\
\hline Low salaries & 2 & External \\
\hline Negative mindset & 1 & Internal \\
\hline Non-availability of good food & 2 & External \\
\hline Planning and basic infrastructure & 30 & External \\
\hline Poor attitudes & 2 & Internal \\
\hline Poor public health system & 18 & External \\
\hline Poverty & 13 & External \\
\hline Religious intolerance & 1 & Internal \\
\hline Stress & 2 & Internal \\
\hline Superstition & 1 & Internal \\
\hline Tribal discrimination/marginalisation & 1 & External \\
\hline Unemployment & 3 & External \\
\hline Uneven wealth distribution & 4 & External \\
\hline Unhealthy and unhygienic lifestyles & 11 & Internal \\
\hline Weak control mechanisms for safety and quality & 7 & External \\
\hline Weak economy & 1 & External \\
\hline Weak government structures & 2 & External \\
\hline Weak legal system & 3 & External \\
\hline Weak security & 11 & External \\
\hline Widespread corruption & 7 & External \\
\hline Wrong priorities & 1 & Internal \\
\hline
\end{tabular}


Reproduced with permission of the copyright owner. Further reproduction prohibited without permission. 